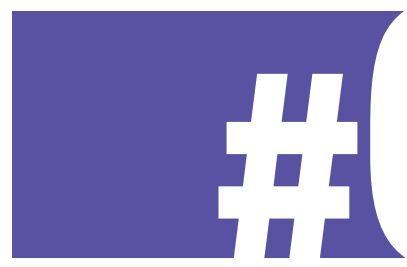

\title{
SUICÍDIO, UM PROBLEMA \\ ORGANIZACIONAL
}

O AUMENTO DOS SUICÍDIOS EM AMBIENTES DE TRABALHO INDICA QUE É HORA DE REFLETIR. NO TRABALHO SÃO CRIADOS SONHOS

E É POSTO À PROVA O POTENCIAL DE CADA UM, MAS A NOVA ORGANIZAÇÃO DO TRABALHO TRANSFORMA CHEFES E SUBORDINADOS EM MEROS CUMPRIDORES DE METAS, E OS COLOCA NUMA GUERRA EM QUE SEMPRE PODE APARECER MAIS UMA VÍTIMA

MARIA ESTER DE FREITAS, professora da FGV-EAESP, ester.freitas@fgv.br

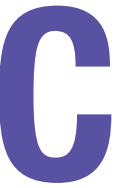
asos de suicídios cometidos por funcionários no ambiente de trabalho ganharam um significativo destaque no noticiário internacional a partir de 2008, com o crescimento do número de casos verificado principalmente na França, em corporações como a France Telecom, a EDF, a Peugeot, a Renault e o Carrefour. Naquele país, tais ocorrências geraram reações imediatas da imprensa e da população, pedindo investigação por parte do poder público e medidas preventivas por parte das empresas, o que deslan- chou um debate envolvendo profissionais de diversas formações.

No Brasil, embora haja indícios de que o problema também está presente, a atitude que até o momento parece estar prevalecendo é a do silêncio. Sem encarar a situação em um debate aberto, as empresas permanecem protegidas dos custos decorrentes de perda de imagem e de cobrança social mais ampla. Enquanto isso, os mortos são tratados como meros casos administrativos. No setor bancário, que é o que tem recebido mais atenção de pesquisadores para estudos sobre assédio moral e, mais 
recentemente, sobre casos de suicídio, teriam sido 253 os casos ocorridos entre 1993 e 2005. Em outros setores, o número é desconhecido.

O suicídio no ambiente do trabalho é um tema de grande atualidade, e ao mesmo tempo muito complexo. Infelizmente não teríamos espaço neste artigo para abordá-lo em sua complexidade, mas gostaríamos de, ao menos, incitar a discussão chamando a atenção para a gravidade do problema. Afinal, o que está acontecendo com o trabalho, que leva as pessoas a se matarem dentro da organização?

\section{TABU}

Temas ligados à morte geralmente causam mal-estar, e dificilmente são tratados com naturalidade pelas pessoas, organizações e sociedades. Quando a morte ocorre como produto da escolha do indivíduo, esse incômodo é ainda maior, pois traz consigo uma sensação de incompetência social, e um enorme sentimento de falha. Afinal, como alguém pode preferir morrer a viver? A surpresa causada pela ocorrência perto de nós nos conduz geralmente a dois questionamentos que são quase clichês: como não percebemos que a situação estava naquele ponto, e o que poderíamos ter feito para evitá-la.

Mesmo tratando-se de um tema pre- sente na Bíblia (como em Sansão e Judas) e que remonta à Grécia e à Roma antigas, além de ter sido analisado por estudiosos como Marx, Durkheim, Freud, Nietzsche, Schopenhauer, Hume e Camus, o suicídio continua um assunto imbricado e, não raro, um tabu. Sua complexidade deriva do fato de ele apresentar múltiplas faces, envolvendo simultaneamente aspectos filosóficos (o sentido da vida), biológicos (o papel dos genes), sociais (contexto relacional amplo e restrito), psíquicos/psicológicos (embate entre pulsões de vida e de morte, saúde mental), jurídicos (quem tem o direito de escolher sobre a vida) e religiosos (a vida como presente divino). Em muitas culturas, é um assunto proibido ou, no mínimo, de mau gosto, sendo o suicida visto como um egoísta ou covarde que não conseguiu lidar com as exigências da vida.

Estudos mostram algumas razões gerais que podem levar pessoas a se matar, sendo as mais comuns doenças graves ou sem esperança de cura; depressão e problemas psíquicos, tais como paranoia, esquizofrenia e outros; problemas financeiros; desemprego; problemas de natureza moral, como culpa e vergonha etc. Se nos últimos anos tem crescido o número de pessoas que cometem suicídio dentro do ambiente de trabalho, esse fato traz duas novidades para a questão: a) são pessoas com emprego, inclusive altamente qualificadas; e b) o lugar escolhido para o ato é o local de trabalho. Isso nos leva a refletir sobre algumas transformações recentes na organização do trabalho e suas consequências.

\section{TRABALHO E SUBJETIVIDADE}

Para a maioria das pessoas, o trabalho significa mais do que uma simples atividade remunerada. Ele possui um papel social, na medida em que por meio dele as pessoas interagem e constroem víncu-

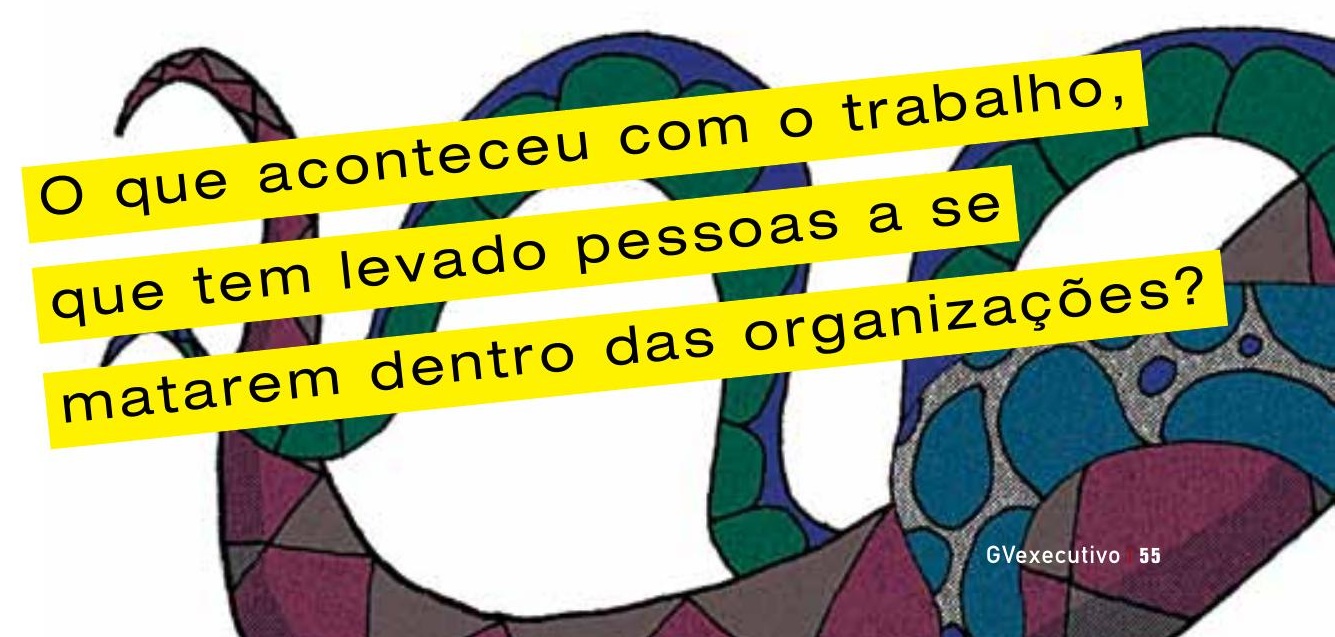


Na França, casos de suicídio

no ambiente de trabalho

ganharam destaque no noticiário

a partir de 2008, com o

crescimento das ocorrências

em grandes empresas

los. Exerce também uma função psicológica, que envolve aspectos de nossa identidade pessoal, social e profissional, além de ser fonte de reconhecimento e autoestima. Possui por fim uma função simbólica por meio da qual representamos a nós mesmos, aos outros e a uma visão de mundo.

O trabalho é uma atividade que nos coloca no centro do palco como atores importantes, pode dar visibilidade às nossas criações, e permite o desenvolvimento de nossos talentos, potenciais e sonhos. Pela convivência com os outros, desenvolvemos sentimentos de solidariedade, cooperação e pertinência a um grupo, bem como podemos esperar o reconhecimento como pessoas singulares e originais no uso de nossas capacidades e energias criativas.

Nesse sentido, o trabalho envolve a nossa vida psíquica, mobilizando nos- sos desejos e sonhos, representando possibilidade de autonomia e independência, favorecendo o desenvolvimento de laços sociais e utilizando a nossa força criativa. Mudanças profundas no conteúdo e no ambiente de trabalho podem causar impactos psicossociais arriscados, que merecem cuidados.

\section{NOVA ORGANIZAÇÃO DO TRABALHO}

O mundo contemporâneo tem passado por profundas mudanças políticas, econômicas, sociais e culturais. O processo de globalização trouxe na sua esteira a necessidade de adaptação de todos os atores sociais, sendo as empresas privadas um desses atores pressionados a fazer ajustes rápidos. Nos anos 1990, houve um intenso movimento de reestruturações organizacionais e privatizações de parte do setor público em diversos países, que ampliou a incorporação tecnológica, elevou a concorrência e mudou a face das qualificações profissionais. Reengenharias foram feitas objetivando enxugar planilhas de custos por meio do uso intensivo de tecnologia, do fechamento de unidades e fábricas, de processos de fusões, aquisições, terceirizações e parcerias, em um processo que só se intensificou com o início do novo século.

$O$ processo traz consequências nocivas ao ambiente de trabalho. Os casos de assédio moral, que ganharam as páginas dos jornais e têm levado muitas empresas ao banco dos réus, são uma das facetas desse fenômeno, como abordado no artigo de Roberto Heloani, neste mesmo número da GV-executivo. Nos últimos anos, foram os suicídios que ganharam evidência e despertam o interesse de alguns especialistas no mundo laboral e em saúde, como atestam os trabalhos dos pesquisadores Christophe Dejours e Florence Bègue (2009), bem como os de Yves Clot (2010).

Mas o que teria acontecido, para levar ao aumento dos suicídios no trabalho? A explicação passa pela nova organização do trabalho que resultou dessas transformações, e que, de forma genérica (não estamos analisando nenhum setor em particular), assumiu a seguinte 
face: as profissões e carreiras tornaramse meras atividades comerciais, e seus executantes, vendedores com metas a cumprir; as relações entre colegas foram quebradas, visto que o controle de metas é individual e a concorrência é de todos contra todos; os chefes respeitados deram lugar a supervisores de metas; a autonomia, interdependência e responsabilidade coletiva é agora responsabilidade individual; o tempo, que era um organizador do trabalho, passou a ser visto como um inimigo a ser vencido; o sentimento de dever cumprido e orgulho pela boa qualidade foram transformados em números a serem atingidos à custa de qualquer sacrifício; o quadro de pessoal ou o coletivo de trabalho agora é composto por um exército de profissionais terceirizados, subcontratados ou temporários; o trabalho como uma fonte de aprendizagem e de cresci- mento tornou-se um trabalho que infelicita. O ambiente de trabalho virou palco de guerra, todos transformados em mercenários pagos a soldo e cada um por si na angústia de sobreviver mais um mês.

As consequências mais visíveis dessas mudanças nos parecem ser: a) o esvaziamento das profissões, do saber e da qualificação, precarizando o trabalho na medida em que este deixa de obedecer a uma lógica de profissão e passa a ser apenas uma lógica de produto, como o bancário, que se torna apenas vendedor de seguros, consórcios e contas; b) ruptura dos laços coletivos e esmagamento da solidariedade, pois a guerra é de todos; c) intensificação do ritmo e avaliação individual, afinal o dinheiro nunca dorme; d) lógica de resultados, gerando álibis permanentes para perversidades de todos os tipos; e) trabalho submisso e sem sentido, qualidade esquecida, condições precárias e temporárias; f) profissionais chantageados e transformados em homens-coisas, numa lógica que é própria do limão espremido até o descarte; g) indivíduos isolados, exaustos, desprezados, humilhados e sem esperança, transformados em alvos preferenciais.

\section{É POSSÍVEL PREVENIR?}

O suicídio é o ápice de uma sequência de episódios degradantes, que podem ser evitados. Infelizmente não temos espaço aqui para expandir a análise, mas podemos dizer que toda prevenção exige a divulgação e o debate. De modo geral, as empresas francesas citadas no início do artigo têm tomado diversas providências, pressionadas pela opinião pública, inclusive envolvendo compromissos de seus CEOs. O Brasil, onde os casos sequer são conhecidos, encontra-se em desvantagem no tocante ao debate e à prevenção. Empresas, sindicatos e imprensa estão entre os agentes que têm um crucial papel a cumprir no encaminhamento do problema. O suicídio não significa necessariamente uma negação da vida, mas apenas daquela vida que está sendo vivida, portanto ele não é um beco sem saída. 